\title{
ARTICLE
}

\section{Platinum-Containing nanocomposites based on Humic substances from brown coal}

\author{
Gania Dolmaa ${ }^{1}$, Galina Petrovna Aleksandrova ${ }^{2}$, Marina Vladimerovna Lesnichaya ${ }^{2}$ \\ Byambajav Nomintsetseg $^{1 *}$, Anatoly Nikolaevich Sapojhnikov ${ }^{3}$, Boris Genadevich Sukhov ${ }^{2}$ \\ Batnasan Bayaraa ${ }^{1}$, Duger Regdel ${ }^{1}$ and Boris Aleksandrovich Trofimov ${ }^{2}$ \\ ${ }^{I}$ Institute of Chemistry and Chemical Technology, Mongolian Academy of Sciences \\ Ulaanbaatar, Mongolia \\ ${ }^{2}$ A.E.Favorsky Irkutsk Institute of Chemistry of Siberian Branch of Russian Academy of Sciences \\ Irkutsk, Russian Federation \\ ${ }^{3}$ A.P. Vinogradov Irkutsk Institute of Geochemistry of Siberian Branch of Russian Academy of Sciences \\ Irkutsk, Russian Federation
}

\begin{abstract}
In the presentreport we look intosynthesized silver and gold-containing nanocomposites based on humic substances. The composition and properties of humic substances isolated from brown coal in Mongolian deposits have beenestablished. The methodology of obtaining platinum-containing nanobiocomposites using a matrix of humic substances is described. Our investigation shows thattheir composition and structure are characterized by a complex of modern physicochemical methods, such as $X$-ray, energy dispersive spectral microanalysis, infrared spectroscopy (IR), ultraviolet spectroscopy (UV), $X$-ray diffraction analysis, Scanning electron microscopy (SEM).
\end{abstract}

Keywords: brown coal; humic substances; nanoparticles; platinum;

\section{INTRODUCTION}

The search for new functional materials is one of the defining characteristics of modern science and technology. Metal nanoparticles (MNPs), in particular, platinum nanoparticles (PtNs) can possess a wide range of properties that can be used for many practical applications. Platinum is one of the rarest and most expensive metals. It has a high corrosion resistancequality and numerous catalytic applications including in automotive catalytic converters and petrochemical cracking catalysts. Platinum nanoparticles are usually used in the form of colloid or suspension in a fluid. They are the subject of extensive research due to their antioxidant properties.

Previously, to begin withwe studied the characteristics of water-soluble silver and gold containing nanocomposites with a variable amount of metal component based on reducing and stabilizing matrix of humic substances isolated from various deposits in Mongolia [1-4]. Their matrices are activated byincreasingthe activity of all studied humic substances in alkaline medium hydrolysis. 
The humic substances of therapeutic mud have the greatest reducing and stabilizing ability from among other investigated objects [5-27]. For gold nanoparticles, the least-oxidized HS isolated from coals have the greatest reducing ability [11]. Humic substances and silverand gold-containing nanocomposites exhibit high antioxidant activity, comparable to wellknown antioxidants [26].

Humic substances from coal and sediments can be defined as surface active substances based on literature and our previousstudies. Many industrially produced humic materials hadlittle or no impact of surface tension, whereas humic substances isolated from natural environments (soil, coal water, sediments) exerted a large impact of surface tension. Surfactants playa major role in the formation of metal-containing nanocomposite.

\section{MATERIALS AND METHODS}

\section{Isolation of humic substances}

Long-term stable platinium-containing nanocomposites have been synthesized based on humic substances extracted from brown coal of Baga Nuur deposit inMongolia. Humic substances isolated from brown coal using alkaline extraction procedure have beenreported by Dolmaa et al.The isolation was carried out as follows: brown coal $(10 \mathrm{~g})$ was dried in air and dissolved in $\mathrm{HCl}(100 \mathrm{~mL}$, $10 \%$ ) solution at room temperature for one hour, and in water bath heated for 2 hours. The mixtureafter coolingwas filtered and washed with distilled water. Residues were extracted with $\mathrm{NaOH}(0.2 \mathrm{~N})$ at $60^{\circ} \mathrm{C}$ overnight. Supernatant were recovered by centrifugation and filtration $\mathrm{pH}$ was adjusted to 1 using $\mathrm{HCl}$ $(0.6 \mathrm{~N})$. Produced humic substances were separated from supernatant and washed with distilled water until Cl- was removed, and then they were driedat $80^{\circ} \mathrm{C}$.

\section{Synthesis Method}

The Pt-containing nanocomposites were synthesized by the reaction of $\mathrm{Pt}$ ions with humic substances in the aqueous alkaline
Due to its high redox potential, humic substances can function as a reducing agent for noble metal ions, including platinum. Chemical methods for synthesizing nanoparticles using platinum hydrochloric acid as precursors and polymeric biomatrices as stabilizers are the most common and are acceptable in the development of promising bio-nanomaterials. Due to potential technological interests of $\mathrm{PtNs}$, the synthesis and study of nanoparticles have been the object of research carried out in the last few years byour team.In particular, studies intonanostructured materials show a strong dependence of their properties on size and shape. For example, the size effect on the catalytical efficiency is known, whilethe perspective effect on catalysis by the shapes of metal nanoparticles is yet to be determinedand so is under investigation [28-31].

medium [3, 5, 8, 10,11]. Humic substances of coal (15 g each sample) were dissolved in an aqueous solution of sodium hydroxide and mixed with platinum precursor solutions of platinum chloride $\left(\mathrm{H}_{2} \mathrm{P}_{\mathrm{t}} \mathrm{C}_{16}\right)$, the reaction was carried out bystirring the solution for 120-180 minutes at a temperature of $90^{\circ}$ Celcius.

The IR absorption spectra were recorded as $\mathrm{KBr}$ pellets on a Bruker Vertex 70 spectrophotometer. The optical absorption spectra of aqueous solutions of nanocomposites and initial humic substances were recorded on a PerkinElmer Lambda 35 spectrophotometer in a quartz cuvette (path length, $1 \mathrm{~cm}$ ).

The X-ray diffraction patterns were recorded onaBrukerD8Advance diffractometer (CuKaradiation, Goebel mirror). The unit cell parameters and CSR for each sample were averaged for three independent measurements and calculated using the DIFFRACplus EVA 13. Software package.

SEM. Scanning electron microscopy was performed on a Hitachi TM 3000 scanning electron microscope with an SDDXFlash 4304 detector. 
HS-coal, (wt \%): C, 53.6; O, 37.1; O / C, 0.69; H, 3.9; Si, 4.9; Al, 2.71; S, 0.4; Fe, 0.9; IR: $3432(\mathrm{OH}) ; 2924(\mathrm{C}=\mathrm{C})$; $2855(\mathrm{C}-$ C); 1801, 1717, $1700(\mathrm{C}=\mathrm{O}) ; 1623(\mathrm{HOH})$,

\section{RESULTS AND DISCUSSION}

Humic substances from studied Mongolian resources are black crystalline powders with ash content (20-22\%). The main mineral elements in all studied humic substances are $\mathrm{Si}$, $\mathrm{Al}, \mathrm{Fe}$ and the amount of $\mathrm{Na}$ increasedto $8.7 \%$ (initially $0.2 \%$ ) caused by formation of sodium humates when the samples were dissolved in alkaline. The degree of oxidation $(\mathrm{O} / \mathrm{C})$ varies in the ranges $0.69-0.92$. IR spectroscopy of platinum containing nanocomposites revealed the following: HS-coal/Pt: IR (v, cm-1): $3428(\mathrm{OH}) ; 2923(\mathrm{C}=\mathrm{C}) ; 2856(\mathrm{C}-\mathrm{C}) ; 1574$ $(\mathrm{OH}), 1445,1380$, (aromatic ring); 1031 (C-O
1455, 1436, 1418, 1418, 1388, 1339 (Ar); 1211 (C-O), 1032 (C-O carbohydrates); 911 ( $\beta$-glycosidic bonds of pyranose rings).

Table 1. Ash elements in platinum containing nanocomposites

\begin{tabular}{|l|c|c|c|c|c|c|c|c|c|c|c|}
\hline Samples & $\begin{array}{c}\text { yield, } \\
\%\end{array}$ & Pt, \% & Na, \% & Si, \% & AI, \% & S, \% & Fe, \% & N, \% & C, \% & O, \% & O/C \\
\hline HS-coal & - & - & - & 4.9 & 2.71 & 0.4 & 0.9 & - & 53.6 & 37.1 & 0.69 \\
\hline HS-coal $^{1}$ & 95.6 & 2.3 & 8.2 & 5.6 & 2.8 & 0.3 & 1.0 & 2.4 & 42.6 & 34.3 & 0.81 \\
\hline HS-coal $^{2}$ & 99.5 & 3.8 & 8.7 & 4.3 & 2.3 & 0.3 & 0.6 & 2.6 & 42.1 & 35.4 & 0.84 \\
\hline HS-coal $^{3}$ & 95.9 & 5.5 & 8.3 & 4.2 & 2.2 & - & 0.4 & 3.5 & 39.4 & 36.3 & 0.92 \\
\hline
\end{tabular}

Presumably, the recovery of platinum from $\mathrm{H}_{2} \mathrm{P}_{\mathrm{t}} \mathrm{Cl}_{6}$ occurs due to oxidizable carbonyl groups with different aliphatic, aromatic and phenolic hydroxyl groups in a significant amount $(2.7-4.1 \%)$ in the composition of HS.This assumption is confirmed by the degree of oxidation $(\mathrm{O} / \mathrm{C})$ of HS fromcoal andthe synthesis of nanocomposites increases by $30 \%$ depending on the source of HS, which is caused by simultaneous hydrolysis and interactive oxidation-reduction of HS with a precursor of platinum. carbohydrates); 911 ( $\beta$-glycosidic bonds of pyranose rings).

The final product yield was high (95-99\%), the amount of platinum in nanocomposite varies by $2.3-5.5 \%$ depending on the amount of precursor and the stabilizing capacity of the HS source (Table 1). Variation ofthe quantitative content of nanoscale metal in the composition of nanocomposites was carried out by changing the ratio of precursor of platinum/HS. Nanocomposites based on all studied samples are capable of stabilizing 1.2 to $5.5 \%$ of platinum in a nanoscale state.
Figure 1 shows the ratio of oxidation state $(\mathrm{O} / \mathrm{C})$ of platinum containing nanocomposites. Comparison of data in the diagram shows that HS and their nanocomposites have a unique molecular composition in the range of 0.69 to 0.92 . This indicates the presence of aliphatic carbonyl- and carboxyl-containing components, which are linearly related to the observed oxygen distribution among HS compounds. 


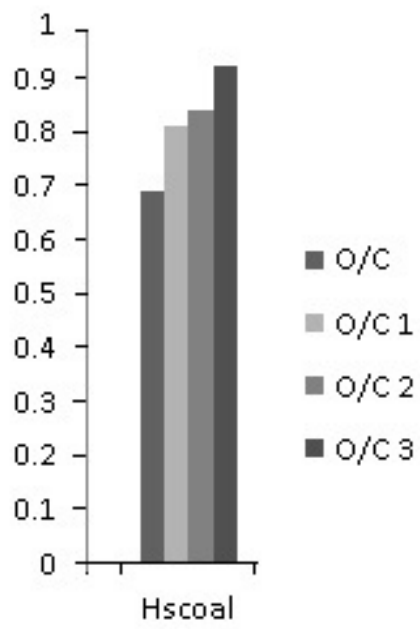

Figure 1. The ratio of oxidation degree $(\mathrm{O} / \mathrm{C})$ of initial $\mathrm{HS}$ and platinum containing nanocomposites: HS extracted from coal (1- 2.3; 2-3.8; 3-5.5\% Pt).

A comparison of data in the diagrams of oxidation degree for silver and gold nanocomposites shows that HS from various sources and their nanocomposites have a similar dependence [8].

The composition and structure of new nanocomposites have been studied using modern physico-chemical methods, including spectral (UV/vis, IR, X-ray phase) analysis.

$\mathrm{X}$-ray diffraction analyses confirm the presence of zero-valence platinum nanoparticles in Pt-HS nanocomposites. The diffraction patterns of the nanocomposites show a halo of an amorphous phase of humic substances in the range of angles $15-30^{\circ}$, and also three intense reflections at $39.8^{\circ}, 46.2^{\circ}$ and $67.4^{\circ}$, referring to the faces of a facecentered cubic platinum lattice.

The average size of the coherent scattering region of platinum nanoparticles of coal humic substances are $6.0 \mathrm{~nm}$ based onXRDanalysisthatusesScherrerequation.

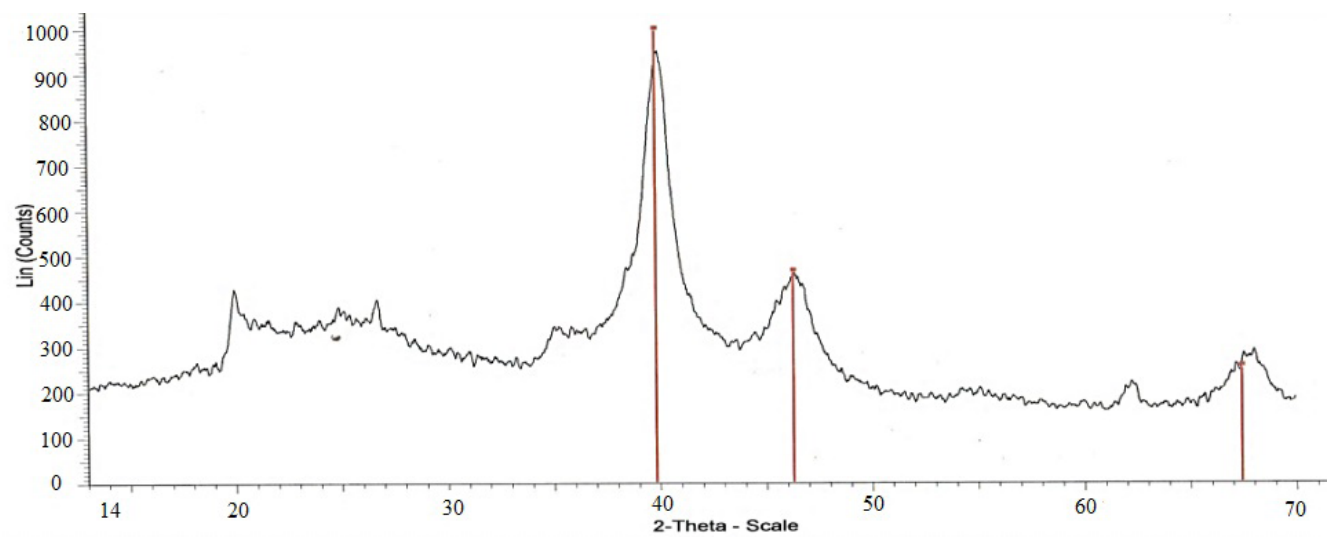

Figure 2. Diffractogram of a platinum nanocomposite based on HS extracted from coal (containing $5.5 \%$ platinum). 
Previous study confirmed that HS is characterized by a high intensity of light absorption, which is due to the presence of double carbon-carbon and carbon-oxygen bonds, whichcorrelates well with the degree of aromatization of the HS.Light adsorption of all samples in the UV-Vis region, a decrease in the absorption intensity with an increase inthe wave length was observed. Plasmon absorption of platinum nanoparticles should be manifested in the region of $220 \mathrm{~nm}$, where HS have a strong absorption (Fig. 3).

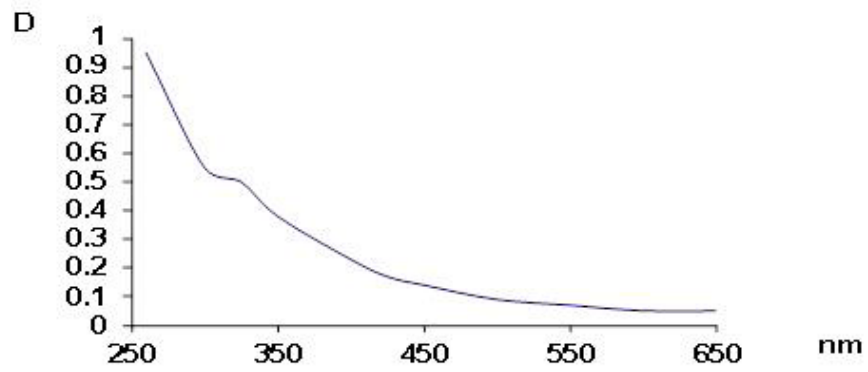

Figure 3. Electronic spectrum of Pt containing nanocomposite based on HS isolated from coal

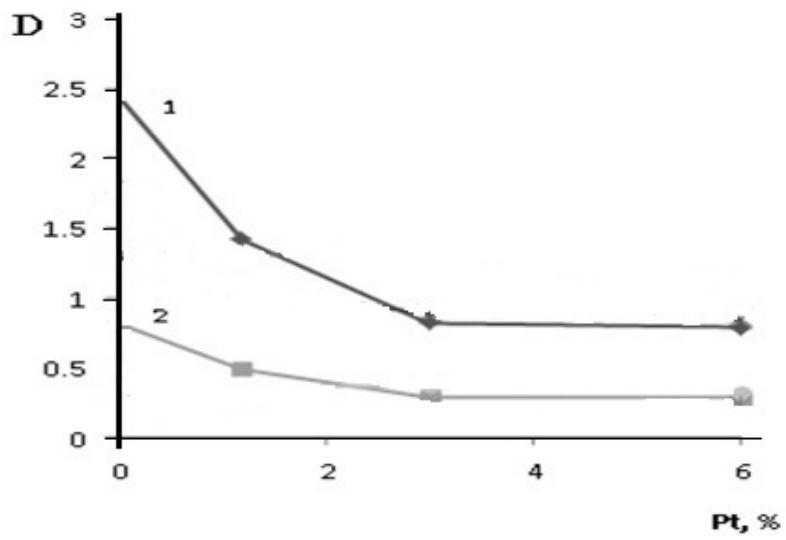

Figure 4. Color input (absorption at 465 and $650 \mathrm{~nm}$ ) of initial HS from various sources withplatinum nanocomposites, (1-HS-coal/465, 2-HS-coal/650)

It is known that plasmon resonance of nanoscale platinum is observed in the $230 \mathrm{~nm}$ region [27]. Since the source HS itself also has high absorption in this region (Fig. 4), it is not possible to use electron spectroscopy data for direct characterization of platinum nanoparticles. 
Table 2. The color factor E465/E650 of platinum nanocomposites based on HS from coal

\begin{tabular}{|c|c|c|c|c|}
\hline \multirow{2}{*}{ Sample } & \multicolumn{4}{|c|}{$\mathrm{E}_{465} / \mathrm{E}_{650}$} \\
\cline { 2 - 5 } & Initial HS & $\begin{array}{c}\mathrm{HS} / \mathrm{Pt} \\
(2.3 \% \mathrm{Pt})\end{array}$ & $\begin{array}{c}\mathrm{HS} / \mathrm{Pt} \\
(3.8 \% \mathrm{Pt})\end{array}$ & $\begin{array}{c}\mathrm{HS} / \mathrm{Pt} \\
(5.5 \% \mathrm{Pt})\end{array}$ \\
\hline HS-coal & 2.99 & 2.90 & 2.85 & 2.85 \\
\hline
\end{tabular}

Signals were observed inIR spectra of nanocomposites in the range of 1800-1600 $\mathrm{cm}-1$ but theydiffer from the spectra of initial HS samples, which indicates a change in theirchemical structure. Thus, in the IR spectra of nanocomposites, the absence of peak in the 1715-1713 and $1704 \mathrm{~cm}-1$ indicates there are aldehyde groups, which is presented in IR spectra of initial HS. This is indicative ofa reduction in the number of aldehyde groups in platinum-containing nanocomposites as a result of their expenditure on metal reduction. The disappearance of absorption intensity at $1700 \mathrm{~cm}-1$, cofactor with a significant increase in absorption at 1385-1379 cm-1 observed in IR spectra of nanocomposites, which were an indication of the oxidative transition of aldehyde groups to carbonyl due to their consumption of metal reduction.

Consequently, the reduction of platinum from the precursor to zero-valent state occurs due to phenolic and alcoholic hydroxyl groups capable of oxidation, which are a significant part of humic substances, as well as carbonyl groups. The phenolic, carboxyl and amino groups present in HS obviously act as stabilizing agents.

A study of the morphology of HS/Pt showed their common unidirectional difference from the morphology of initial HS to the decrease in particle size and greater looseness of the precipitate, as demonstrated by the examples of nanocomposites of platinum based on coal HS (Figure 5).
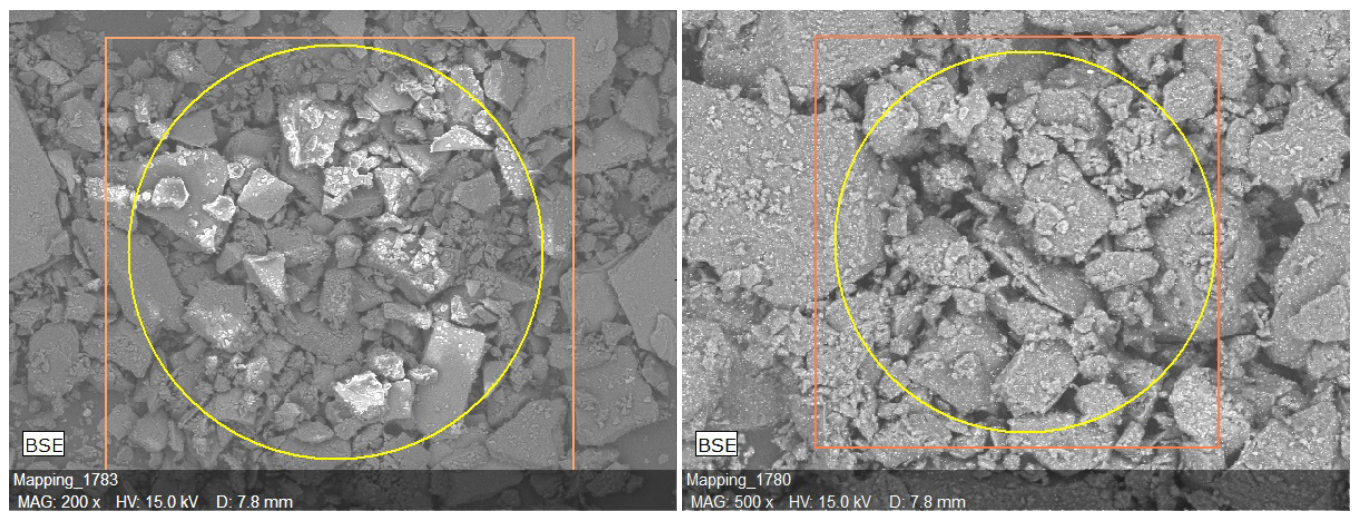

Figure 5. Morphology of initial HS sample (magnified 200) and platinum nanocomposite based on HS coal (magnification 500).

Thus, the use of humic substances of various origins as a matrix makes it possible to obtain long-term stable nanocomposites containing nanoparticles of zero-valent platinum, characterized by the same type of loosened morphology of powder samples with a lighter color as compared to the initial HS. 


\section{CONCLUSIONS}

Due to its high redox potential, humic substances can function as a reducing agent for noble metal ions, including platinum. Chemical methods for synthesizing nanoparticles using platinum hydrochloric acid as precursors and polymeric biomatrices as stabilizers are the most common and acceptable practice in the development of promising bionanomaterials.

The new methodological approach developed by our team, based on the specific adsorption of biogenic polymer to the surface of nano-sized metal aggregating from aqueous solution of inorganic nuclei, which provides self-organization of the resulting hybrid inorganic-organic nanostructures with fine regulation of their dimensionality, can be used to simulate the formation of organomineral nanocomposites in nature and can beused for the analysis of the origin of dispersed ore formations in geology.

\section{REFERENCES}

1. E.V. Ariunushkina, Guide to chemical analysis of soil. M: Publishing. M.S.U, 1961.p. 491.

2. G. Dolmaa, Sh. Tserenpil, U. Ugtakhbayar, 'Method of humic substances isolated from peloid" patents. 2004. №.8. (147). p. 13.

3. G. Dolmaa, G.P. Aleksandrova, U. Enkhbadral, L.A. Grishchenko, B. Sukhov, D. Regdel,B.A. Trofimov "Creating a hybridized nanocomposite with silver based on multifunctional natural polymers" Proceedings of the Mongolian Academy of Sciences, 2010, vol. 195, no. 1, pp. 26-37.

4. G. Dolmaa, Sh. Tserenpil, U. Ugtakhbayar, "Method of humic substances isolated from peloid", MNS 5442:2005.

5. G. Dolmaa, G. P. Aleksandrova, M.V. Lesnichaya, B. Nomintsetseg, G. Ganzaya, B. Bayaraa, B.G. Sukhov, D. Regdel, B.A.Trofimov. "Properties of Humic Substances Isolated From Different Natural Sources". /Mongolian J. Chem. 2013. V. 14. N 40. p.51-56.

6. G. Dolmaa, G. P. Aleksandrova, M.V. Lesnichaya, B.G. Sukhov, D. Regdel, Trofimov B.A. "Possibility of isolated humic substances and properties". Chemistry-2013. 2013.11.08

7. G. P. Aleksandrova,G. Dolmaa, M. V. Lesnichaya, T. I. Vakul'skaya, G. F. Prozorova, B. G. Sukhov, D. Regdel, B. A. Trofimov. "Structural Features of Brown Coal Humic Substances". Conference Thesis: For an International Russian-Kazakh Symposium "Coal Chemistry and Ecology of Kuzbass." October 2014. p. 11.

8. M. V. Lesichnaya, G. P. Aleksandrova, G. Dolmaa, B. Nomintsetseg,A, N, Sapozhnikov,B.G. Sukhov, D. Regdel, B.A.Trofimov. //Structural organization of humic substances of therapeutic muds, coals and shales in the process of alkaline hydrolysis//.Geography and Natural resources 2016. №6. pp.70-75.

9. N.I. Tikhonov, S.S. Khutsishvili*, M.V. Lesnichaya, G. Dolmaa, T.I. Vakul'skaya, G.P. Aleksandrova, B.G. Sukhov. "Paramagnetic properties and antioxidant activity of metalcontaining bionanocomposites based on humic substances".Magnetic Resonance in Solids. Electronic Journal (MRSej), 2016, Vol. 18, Issue 1, P№16104, pp.1-5.

10. G. Dolmaa, M.V. Lesnichaya, G. P. Aleksandrova, B. Nomintsetseg, E. Urantsetseg, B.G. Sukhov, D. Regdel, B.A.Trofimov. "Possibility of gold containing nanocomposite based on humic substances and their properties" Proceedings of the Mongolian Academy of Sciences. 2014. №2 (210). pp. 66-71

11. M. V. Lesnichaya, G. P. Aleksandrova, G. Dolmaa, A. N. Sapozhnikov B. G. Sukhov, D. Regdel, and Academician B. A. Trofimov. "Features of Gold Nanoparticle Formation in 
Matrices of Humic Substances of Different Origin”. Doklady Chemistry 2015, Vol. 460, Part I, pp. 13-16. ИФ-0,41398.

12. S. Spartak Khutsishvili, Ph.D; Nikolay I. Tikhonov; Marina V. Lesnichaya, Ph.D; GaniaDolmaa, Sc.D; Tamara I. Vakul'skaya, Ph.D; Galina P. Aleksandrova,Ph.D; Boris G. Sukhov, Ph.D. "Paramagnetic bioactive silver- and gold-containing nanocomposites based on humic substances“.Functional Materials Letters. Vol. 10, No. 2 2017, 1650077 (4 pages), World Scientific Publishing Company DOI:10 1142/S1793604716500776 ИФ-1,606

13. B. A. Trofimov, G. P. Aleksandrova,M. V. Lesnichaya, G. Dolmaa, B. G. SukhovN. N. Pogodayeva, S. S. Khutsishvili, G. B. Borovskii, T. A. Penzina,D. N. Olennikov, S. A. Zilov, D. B. Baskakov,B. Nomintsetseg, G. Ganzaya., "Structure - physicochemical and biological properties of "nanobiocomposites". Scientific Cooperation of the Siberian Branch of the Russian Academy of Sciences with Mongolia in the First Half of the 21st century.2015. pp. 7-26.

14. B. A. Trofimov, G. Dolmaa, G. P. Aleksandrova, M. V. Lesnichaya, B. G. Sukhov, D. Regdel. "Creation of new remedies on the basis of healing mud humic substances". Traditional Medicine: Ways of Integration With Modern Healt Care Proceedings Of The VI International Scientific Conference. August 15-17, 2013, Ulan-Ude, Russia.

15. M. V. Lesnichaya, G. P. AleksandrovaG. Dolmaa, B. G. Sukhov, D. Regdel, B. A. Trofimov. "Silver-containing nanocomposites on the basis of humic substances and their antioxidant activity". 2nd International Scholarly Conference on Nanotechnology and Nanotoxicology, Baikal, August 15-19, 2013.

16. B. A. Trofimov, D. Regdel, G. P. Aleksandrova, M. V. Lesnichaya, G. Dolmaa,B. G. Sukhov, N. N. Pogodayeva, T. I. Vakul'skaya, S. S. Khutsishvili, G. B. Borovskii, T. A. Penzina, S. A. Zilov, D. B. Baskakov,B. Nomintsetseg,G. Ganzaya //Structure - physicochemical and biological properties of ${ }^{*}$ nanobiocomposites// Materials of a scientific-practical conference on the result of a contest of joint Russian-Mongolian projects. Ulaanbaatar, 1819 November2013. pp.42-55.

17. G.Dolmaa, G.P.Aleksandrova, M.V.Lesnichaya, A.N.Sapozhnikov, B.Nomintsetseg, B.G.Sukhov, D.Regdel, B.A.Trofimov. "Synthesis and Physicochemical properties on nanocomposite based on humic substances". 4th International Conference on Chemical Investigation and Utilization of Natural resources, Mongolia, (ICCIUNR 2016), UB, 8-10 July 2016, p.98.

18. G. Dolmaa, G.P. Aleksandrova, M.V. Lesnichaya, B. Bayaraa, E. Urantsetseg, G. Ganzaya, G.Tserenhand, B. Nomintsetseg, B.G. Sukhov, D. Regdel, B.A. Trofimov."Biological activity of nanocomposities based on humic substances". 4th International Conference on Chemical Investigation and Utilization of Natural resources, Mongolia, (ICCIUNR 2016), UB, 8-10 July 2016, p.32.

19. S.S. Khutsishvili, N.I. Tikhonov, M.V. Lesnichaya, G. Dolmaa, T.I. Vakul'skaya, G.P. Aleksandrova, B.A. Trofimov."Paramagnetic nanocomposites based on humic substances with strong stabilization properties of silver and gold nanoparticles"." 4th International Conference on Chemical Investigation and Utilization of Natural resources, Mongolia, (ICCIUNR 2016), UB, 8-10 July 2016, p.81.

20. S.Spartak, Khutsishvili, Nikolai I.Tokhonov, Marina V.Lesnichaya, G. Dolmaa, Tamara I. Vakyl'skaya, Galina P. Aleksandrova, Boris G.Sukhov. "Humic Substances as Matrixes for Obtaining of the Silver-Containing Bionanocomposites with Antioxidant Activity". APES 2016 Symposium, 28 August-02 September 2016, Lake Baikal, Irkutsk, Russia OR-18.

21. Spartak S. Khutsishvili, Nikolai I.Tokhonov, Marina V.Lesnichaya, G. Dolmaa, Tamara I. 
Vakyl'skaya, Galina P. Aleksandrova, Boris G.Sukhov. "Nanocomposites Based on Humic Substances with Antioxidant Activity and Strong Stabilization Properties of Silver Clusters Ag”. 24thInternational Conference on Magnetic Resonans in Biological Systems. 21 August-26, 2016, Pos 310, Kyoto, Japan.

22. G. P. Aleksandrova, M. V. Lesnichaya, G. Dolmaa,B. G. Sukhov, N. N. Pogodayeva, T. I. Vakul'skaya, S.S. Khutsishvili,G. B.Borovskii, B. A. Tromifov,

23. D.Regdel, B.Nomintsetseg. "Multipurpose metal-containing nanobiocomposites based on humic substances of various origins". International Joint Conference on Organic Chemistry. The Baikal Reading-2017”. 27 August to 2 September2017. Irkutsk.

24. G. Dolmaa, G. P. Aleksandrova,M. V. Lesnichaya,B. G. Sukhov, S. S. Khutsishvili, T. I. Vakul'skaya, G. F. Prozorova, B. Nomintsetseg, G. Ganzaya, G. Tserenkhand, D. Regdel, B. A. Trofimov. //Plenary report: Synthesis and properties of humic-based nanocomposites//. Thesis of the"Fourth International Reading Commemorating Academician A. E. Favorskii. Irkustk, 17-19 February, 2016.

25. G. Dolmaa, M. V. Lesnichaya, G. P. Aleksandrova, B. G. Sukhov, D. Regdel, B. A. Trofimov. //Evaluation of the antioxidant activity of humic substances from various natural sources of Mongolia//. Far Eastern Academy of Sciences2013 Vol.453.№5. pp. 511-512.

26. G. Dolmaa, M.V. Lesnichaya, G.P. Aleksandrova, B.G. Sukhov, D. Regdel, and Academician B. A. Trofimov. "Estimation of the Antioxidant Activity of Humic Substances from Various Natural Sources of Mongolia". Doklady Chemistry, 2013, Vol. 453, parts 1-2. pp.268-269.

27. G. P. Aleksandrova, M. V. Lesnichaya, G. Dolmaa, I. V. Klimenkov, B. G. Sukhov, D.Regdel, B.ATrofimov. //Silver-containing nanocomposites with antioxidant activity based on humic substances of various origin// Academy of Sciences News. Chemistry Series, 2017, №1.pp.143-149.

28. B. G. Yershov. “"Nanoparticles of metals in aqueous solutions: electronic, optical and catalytic properties "Metal nanoparticles in aqueous solutions: electronic, optical and catalytic properties". Jorunal Russian Chemstry. (J. Ros. Chem. about-vaim. DI. Mendeleev) 2001. Vol. XLV. № 3. pp. 20-30.

29. A.T. Bell. Science 299 (2003) 1688.

30. A. Cheung, G. de M. Azevedo, C.J. Glover, D.J. Llewellyn, R.G. Elliman, G.J. Foran and M.C. Ridgway. Appl. Phys. Lett. 84 (2004) 278.

31. P.J. Ferreira, O.G.J. Ia, Y. Shao-Horn, D. Morgan, R. Makharia, S. Kocha and H.A. Gasteiger. J. Electrochem. Soc. 152 (2005) A2256.

32. Y. Shao-Horn, W.C. Sheng, S. Chen, P.J. Ferreira, E.F. Holby and D. Morgan. Top. Catal. 46 (2007) 285. 